\title{
7 \\ Wider Horizons: \\ Fostering a Culture of Undergraduate Research
}

Roxanne Harde \& Neil Haave

University of Alberta

This essay synthesizes our roundtable discussion about how to develop a campus culture of undergraduate research. Our discussion began with descriptions of the University of Alberta, Augustana's initiatives: Independent Studies courses, the Student Academic Conference, and summer research assistantships. Common concerns from roundtable participants included whether or not student access to undergraduate research should be limited by grade point average, how to implement undergraduate research from first to final year of student degree programs, how to fund undergraduate research, and finally how to approach undergraduate research across the academy.

\section{Introduction}

$\mathrm{O}$ $\mathrm{n}$ the one hand, undergraduate research might seem more easily facilitated at large medical/ doctoral institutions where graduate students provide models for their undergraduate counterparts. On the other hand, when graduate students are available and need sources of funding, undergraduates are generally not hired as research assistants; although this pattern may change as the Tri-Council Agencies (the major government granting agencies in Canada: NSERC - Natural Sciences \& Engineering Research Council, SSHRC - Social Sciences \& Humanities Research Council, and CIHR - Canadian institutes of Health Research) look ever more favourably on undergraduate researchers. The idea of building a culture of undergraduate research is sound. The academy can only benefit by widening the horizons of these students and encouraging them to see themselves as independent researchers/learners (Grobman, 2009; Lei \& Chuang, 2009; Lopatto, 2007; Partridge \& Sandover, 2010; Richman \& Alexander, 2006; Seymour, Hunter, Laursen, \& DeAntoni, 2004). Although difficulties with undergraduate research (e.g. undergraduate students take time to train, faculty not always rewarded for undergraduate supervision, cost of one-onone mentoring, inadequate training) have been documented (Brown, 2006; Dolan \& Johnson, 2010; 
Merkel, 2003). Overall, the idea of undergraduates as researchers has been gaining currency for some time across Canada, even as faculty members and administrators seem uncertain about how to support these endeavours in ways that benefit the students, their faculty mentors, and the institution as a whole.

\section{The Augustana Context}

Both authors are Associate Deans, Teaching and Research, and faculty members who work with undergraduate researchers and administrators on building a culture of undergraduate research on a small liberal arts and sciences campus at the University of Alberta. Our roundtable grew out of the challenges we face on a daily basis as we work to expand and entrench undergraduate research on our campus. This essay synthesizes the discussion at our roundtable, beginning with descriptions of Augustana's initiatives - Independent Studies courses, the Student Academic Conference, and summer research assistantships - and correspondent questions and concerns. We end with clearer ideas about specific challenges that need to be addressed, and in which areas of scholarship of teaching and learning might support undergraduate research on Canadian campuses.

\section{Independent Studies courses}

Independent Studies courses, one-on-one instruction/ collaboration undertaken by faculty and students across the disciplines, form the core of undergraduate research at Augustana. With a student population of approximately 1000 , we generally have between 15-30 of these courses per term (from Fall 2006 to Winter 2011 the average per term was 24). Listed in the calendar as Independent Studies (or Directed Studies or Readings), students negotiate their course with the instructor of their choice, and must then apply for departmental permission for the course to proceed. Generally, these courses include weekly meetings; a large amount of independent work, whether in the lab or the library; several short assignments; a substantial term assignment; and presentation of the research at our term-end Student Academic Conference.
Our concerns about Independent Studies courses, which we face with the rest of the administrative team that comprises our Chairs' Council, are with the variation and disparity that these courses have from one instructor to the other. While Independent Studies courses are about mentoring researchers, some instructors approach the task by giving students the barest of guidance, throwing them in the deep end as it were, while others hold each students hand throughout the term. We also see too much variance in the work produced, particularly with the depth of theoretical struggle expected, and quality of final project. Even in the light of disciplinary differences - technique, theory, and practice - we feel there must be some standard that students in these courses must attain for their work to be seen as successful undergraduate research.

\section{Student conferences}

At the end of every term, we hold the Student Academic Conference, which has grown from a showcase for only Independent Studies students in 1994 to a campus-wide event that includes individual Independent Studies presentations, entire classes presenting team-based research, posters from a variety of disciplines, and creative projects. As the Student Academic Conference has developed, it has taken on the trappings of both professional meeting (abstracts, program) and celebration (festive decorations, food and drink served during the poster session). It works exceptionally well in attracting new undergraduate researchers and faculty mentors as it models (mostly) successful undergraduate research. One challenge we have faced in developing our Student Academic Conference is its timing. Currently, we hold it on the Monday evening during the last week of classes, which seems to best balance the ability to attract faculty, students, and community members. In the past, we have tried making it an afternoon event on the day before exams but have found that it was difficult to entice many to attend: many students go home to study, faculty are busy preparing exams or marking term work, and community members are unable to take time from work. As our Student Academic Conference grows we will need to increase the number of concurrent sessions, which will 
produce its own set of challenges (e.g., the inability to attend all the presentations of interest, expanding the presentation rooms outside one contiguous building, ensuring fair judgement of all students nominated for our Outstanding Independent Work award).

\section{Undergraduate summer research assistantships}

The number of summer research assistantships continues to grow on our campus. Typically, these are 15-week, full-time positions and are financed through various funds that come with different sets of criteria. For example, students who hold positions funded by the Roger S. Smith awards must include a program of independent research in their application, which must be supported by their faculty supervisor. The student then completes the program while working for that instructor. Students hired by the holders of internal grants from the University of Alberta or external grants, such as the Tri-Councils agencies, generally work only on their supervisor's research, and not their own. However, faculty members often precede or follow the supervision of a summer research assistant with an Independent Studies course with that student. Presently, we grapple with finding additional funding to cover the ever-growing number of students who want these positions, largely as a way to prepare themselves for graduate and professional programs, and faculty who need the research support. We also need to investigate ways in which we can attach a summer assistantship to an Independent Studies course that would see the student receive credit but not a salary as they conduct their own research and work for an instructor. Enabling every one of our summer research assistants to do at least some of their own research is another of our concerns.

\section{The Roundtable}

\section{Should GPA determine students' enrollment in Independent Studies?}

While many of our specific concerns were common to the roundtable discussion group, we found that we all shared a number of more global challenges surrounding undergraduate research. In the interests of widening the horizons of all students, not just an elite few, we considered questions about who gets to do undergraduate research. How do we decide which students have access to an Independent Study? Should it hinge on students' grade point average (GPA)? While the literature says it should not (Kinkead, 2003), at Augustana, it commonly does. We know from experience that a lower GPA does not necessarily mean that students will be unsuccessful in an Independent Study. Further, students with higher GPAs occasionally fail to rise to the challenge of an Independent Studies course. Our initial studies have gathered students' preIndependent Studies GPA since 2005 at Augustana, compared them to the subsequent final grade in their Independent Studies course, and found that $42 \%$ of their Independent Studies grade is correlated to their prior GPA $(\mathrm{p}<0.001, \mathrm{n}=201)$. Thus, prior GPA can somewhat predict how well a student will perform in an Independent Studies course, but clearly it is not the only factor.

\section{Funding undergraduate research}

Funding undergraduate research was also a common challenge. From unexpected expenses associated with directed studies in the sciences to finding research assistantships for deserving students and their faculty supervisors, participants struggled with how to balance economic reality with worthy programs. Should undergraduate research be funded by the department, faculty research grants, specific scholarships, or levied student fees? The consensus seemed to be that it would, by necessity, be a mix.

\section{Scaffolding undergraduate research across the degree program}

Our roundtable discussion also touched on how to incorporate undergraduate research in first- and second-year courses. We generally agreed that building research into upper-year courses was easy enough but also felt that scaffolding undergraduate research into students' first two years would better prepare them for a subsequent Independent Studies course. 
In short, there is interest in teaching students to be independent learners/researchers before throwing them in the thick of an Independent Studies course or the demands for research in an upper-year course. The literature describes examples of research skills courses being attached to student research projects, but none discuss approaches for tiering research training across all four years of a degree program (Balster, Pfund, Rediske, \& Branchaw, 2010; Kight, Gaynor, \& Adams, 2006; Rasche, 2004; Snellman, Krueger, \& Unangst, 2006).

\section{Knowledge creation is the heart of undergraduate research}

Participants also discussed the nature of undergraduate research in the Fine Arts. Although it was acknowledged that the nature of the Fine Arts endeavour is apparently different from research in the Humanities, Social, and Natural Sciences, fundamentally it is still focused on the same thing: the creation of knowledge. This does raise the issue of how we compare different approaches to the creation of knowledge, experiential or revealed. Given that consistency even within a discipline can be a problem, how do we find standards to evaluate the appropriateness of the project, its scope, the difficulty of theory, the methods of data collection, and its evaluation across the disciplines? We agreed that further study is needed on both incorporating research into freshman and sophomore courses, and on methods of evaluation.

\section{Conclusion}

The most significant outcome from our roundtable was identifying that undergraduate research needs to be considered with a wider horizon: knowledge creation. If this is the heart of undergraduate research, then the entire academy may find a place for undergraduate research. The challenges of better institutionalizing undergraduate research were shared by many institutions and indeed are not unique to Augustana. Finding ways of rewarding undergraduate supervision, financing undergraduate research, and scaffolding it across all years of students' degree programs will help to embed this high impact educational practice (Kuh, 2008) within university culture.

\section{References}

Balster, N., Pfund, C., Rediske, R., \& Branchaw, J. (2010). Entering research: A course that creates community and structure for beginning undergraduate researchers in the STEM disciplines. CBE - Life Sciences Education, 9(2), 108-118.

Brown, D.R. (2006). Undertaking chemical research at a community college. Journal of Chemical Education, 83(7), 970-972.

Dolan, E.L. \& Johnson, D. (2010). The undergraduate-postgraduate-faculty triad: Unique functions and tensions associated with undergraduate research experiences at research universities. CBE - Life Sciences Education, 9(4), 543-553.

Grobman, L. (2009). The student scholar: (re) negotiating authorship and authority. College Composition and Communication, 61(1), 175-196.

Kight, S., Gaynor, J.J., \& Adams, S.D. (2006). Undergraduate research communities: A powerful approach to research training. Journal of College Science Teaching, 35(7), 3439.

Kinkead, J. (2003). Learning through inquiry: An overview of undergraduate research. New Directions for Teaching and Learning, 93(Spring), 5-17.

Kuh G.D. (2008). High impact educational practices: What they are, who has access to them, and why they matter. American Association of Colleges and Universities, Washington, DC. 
Lei, S.A. \& Chuang, N.K. (2009). Undergraduate student assistantship: A comparison of benefits and costs from faculty and students' perspectives. Education 130(2), 232-240.

Lopatto, D. (2007). Undergraduate research experiences support science career decisions and active learning. CBE - Life Sciences Education, 6(4), 297-306.

Merkel, C.A. (2003). Undergraduate research at the research universities. New Directions for Teaching and Learning, 93, 39-53.

Partridge, L. \& Sandover. S. (2010). Beyond 'listening' to the student voice: the undergraduate researcher's contribution to the enhancement of teaching and learning. Journal of University Teaching and Learning Practice, 7(2).

Rasche, M.E. (2004). Outcomes of a research-driven laboratory and literature course designed to enhance undergraduate contributions to original research. Biochemistry and Molecular Biology Education, 32(2), 101-107.

Richman, K.A. \& Alexander, L.B. (2006). Ethics and research with undergraduates. Ethics and Education, 1(2), 163-175.

Seymour, E., Hunter, A.B., Laursen, S.L., \& DeAntoni, T. (2004). Establishing the benefits of research experiences for undergraduates in the sciences: First findings from a three-year study. Science Education, 88(4), 493-534.

Snellman, E., Krueger, J.A., \& Unangst, E.T. (2006). Moving research into the classroom: Successful adaptations at a service academy. Journal of College Science Teaching, 35(5), 32-36.

\section{Biographies}

Roxanne Harde is Associate Professor of English, Associate Dean (Research), and a McCalla University
Professor at the University of Alberta, Augustana. Her work with undergraduate research assistants and independent studies students has enriched her own research on nineteenth-century American literature and sparked an interest in studying the best practices of undergraduate research.

Neil Haave is Associate Professor of Biology and Chemistry at the Augustana Campus of the University of Alberta in Camrose and has been teaching there since 1990. His interest in undergraduate research stems from being both a supervisor of Independent Studies courses and also as Associate Dean (Teaching) with responsibility for the Student Academic Conference. 